\title{
Sidewalk infrastructure assessment using a multicriteria methodology for purposes of maintenance planning
}

\author{
Nuno Sousa ${ }^{1}$, João Coutinho-Rodrigues ${ }^{* 2}$, Eduardo Natividade-Jesus ${ }^{3}$ \\ ${ }^{1}$ MSc, PhD, Invited Assistant Professor, Department of Sciences and Technologies, Open University, Portugal. \\ Researcher INESC-Coimbra. E-mail: nsousa@uab.pt \\ ${ }^{2}$ CEng, MSc, PhD, Aggr, Full Professor, Department of Civil Engineering, Faculty of Sciences and \\ Technology, University of Coimbra, Portugal. Researcher INESC-Coimbra. Corresponding Author. E-mail: \\ coutinho@dec.uc.pt \\ ${ }^{3}$ CEng, MSc, PhD, Assistant Professor, Department of Civil Engineering, Polytechnic Institute of Coimbra, \\ Portugal. Researcher INESC-Coimbra. E-mail: ednativi@isec.pt \\ * Corresponding author
}

ABSTRACT

Sidewalks constitute the main guideway for the walking mode of transport and serve as a fundamental infrastructure for personal travel including commuting. This is because practically every motorized trip is preceded or concluded by nonmotorized travel. The assessment of sidewalk performance, in the sense of its suitability for walking, involves consideration of multiple aspects, whose precise treatment requires in turn the use of multicriteria methods to support decisions. This article proposes a multicriteria methodology for this purpose, thus setting the stage for subsequent agency decision regarding maintenance strategy development. The methodology is based on a set of infrastructure attributes, directly intervenable by these authorities, and uses the ELECTRE TRI method to assign sidewalks under study to performance classes. It is practical to use and can be applied to any city, at any scale. The approach is thoroughly discussed, and demonstrated for a case study comprising several sidewalks in the city of Coimbra, Portugal. The results indicate that a considerable fraction of these sidewalks is in mediocre condition, and the multicriteria classifying methodology readily suggested intervention strategies, effectively aiding to the decision making.

Keywords: Pedestrian infrastructure assessment, Sidewalks, Multicriteria analysis, Decisionmaking tools, Maintenance planning 


\section{Introduction}

Walking is an active mode of transport used by everybody, everyday, for multiple purposes, including commuting, and as the basic connector mode between all other modes of transport. Sidewalk networks are fundamental urban transportation infrastructures because they provide the main guideway for this important transportation mode.

Infrastructure systems are, in general, perceived as elements performing key societal and economic functions. They involve high costs, tight budgets, and decisions resulting in serious consequences (Mishalani \& McCord 2006). Consistent with this realization, agencies strive to provide funds for transportation infrastructure maintenance, but such resources are insufficient, leading to the need for developing and deploying adequate methods to support an effective management of those infrastructures (Schofer et al. 2010). This requires in turn condition assessment, deterioration modeling, and maintenance decision-making, as recognized by (Mishalani \& McCord 2008). Infrastructure condition assessments provide key information for decision makers to monitor their respective quality, which is essential for subsequent planning of maintenance actions. In what concerns e.g. roadway pavement and bridges, the literature is rich in condition assessment and management methods. However, as recognized by some authors (e.g. Gharaibeh \& Lindholm 2014), such methods are missing for other road related resources such as roadside assets. Sidewalks, despite their omnipresent existence as a primary infrastructure, have not captured the attention of so many researchers, usually more concerned with infrastructures that, at least at first sight, may impose more intense danger for life and property of the respective (motorized) users.

Further motivation to cover for the literature gap in sidewalk assessment tools is the increasing interest in active travel modes witnessed by the last decades, prompted by sustainability worries, traffic congestion and health issues (Woodcock et al. 2007). Indeed, in recent studies dedicated to the evaluation of the performance of European cities, the percentage of journeys to work not done by car is considered a quality of life indicator (Morais \& Camanho 2011). The walking mode is an active travel mode that is favoured for small trips, of up to $1 \mathrm{~km}$ (Millward et al. 2013; Seneviratne 1985), a distance which is 
expected to increase if proper infrastructural facilities are provided (Rahul \& Verma 2014). It increases physical activity, is non-polluting and socially inclusive, and poses little danger to others. Because walking is also the most basic travel mode, it will always have a considerable share among all transport modes, for people of all ages and social status. It is therefore natural and desirable that municipal decision makers provide pedestrians with adequate infrastructures for exercising their choice for this mode, especially if they wish to foster that choice (Sayyadi \& Awasthi 2013).

There has also been a surge of interest lately in the concept of walkability, a concept whose definition in the literature is not precise, but which can be broadly described as the extent to which the built environment is walking-friendly (Abley 2005) or, more strictly, as "a 'match' between residents' desires and expectations for types of destinations, their willingness to walk a given distance and the quality of the required path" (Manaugh \& El-Geneidy 2011). A lot of research has been done on how to define, assess, compare and improve a neighborhood's walkability indexes (Ewing \& Handy 2009; Gallin 2001; Kelly et al. 2011; Moura et al. 2014; TRL 2003), including from a medical viewpoint (Cerin et al. 2006; Ewing et al. 2006; Saelens et al. 2003), or focusing on impaired people (Rodrigues et al. 2012). Indeed, walkable neighborhoods register a higher share of walking as transport mode, at least for non-work trips (Cervero \& Radisch 1996), thus contributing to achieve the aforementioned environmental and health benefits (Frank et al. 2006). Walkability indicators often include sidewalk-related factors in their definition (see e.g. references above and (Park 2008) and (Clifton et al. 2007)), thus increasing the need to consider this infrastructure.

The rising importance of the walking mode, a trend which is expected to continue, especially if its supporting infrastructure is improved (Buehler \& Pucher 2012; Gase et al. 2015; Pucher \& Buehler 2010), makes it a natural necessity to assess the condition of the pedestrian network infrastructure, of which sidewalks are perhaps the most important element. It is in this context of rising importance of walking and need for judicious budget spending that the present research is presented, as a tool to evaluate sidewalk performance, thus setting the stage for subsequent improvement actions, which usually take the guise of prioritization schemes. 
The assessment of sidewalk performance is however a multidimensional task, as there are several technical aspects to be considered, as well as non-technical ones, all contributing to a smooth and pleasant walking experience. Multicriteria aspects are in fact common in relation to transportation engineering problems (Angulo et al. 2012; Bai et al. 2012; Current \& Marsh 1993; Current \& Min 1986; Gosse et al. 2012; Lu \& Tolliver 2013; Sadek et al. 1999) and built environment issues (Bana-e-Costa et al. 2008; Mulliner et al. 2013). Multicriteria sidewalk performance issues appear in some walkability and pedestrian level of service studies but they are approached in a very simple manner (Gallin 2001; TRL 2003), usually by merely summing up weighted scores on the various criteria, which may lead to mismatches in the decision due to the compensatory nature of such methods (i.e., a very bad performance in an attribute may be completely compensated by a very good one in another attribute). A more substantive treatment is that of Khisty (1994), but it does not focus exclusively on criteria that are easily intervenable by municipal authorities, nor does it use the multicriteria methods advocated herein.

The methodology proposed in this article concentrates on engineering aspects of maintenance actions, and integrates various technical information and stakeholder preferences (Kabir et al. 2014 ) in a non-compensatory manner. More specifically, the methodology evaluates sidewalk performance by classifying them into categories reflecting overall performance status using the ELECTRE TRI method (Mousseau et al. 2001; Yu 1992). This method was selected because it mimics aspects of human judgment, and has been used as an appropriate technique to assess the conservation status in other engineering problems (Natividade-Jesus et al. 2013). Furthermore its outcome is simple to interpret and to use when planning for maintenance actions. To the best of our knowledge, it is the first time that such methods are used for sidewalk performance assessment and management planning.

The criteria scoring was developed with the chief concern that data collecting should be simple and straightforward, so as to allow for quick, large scale cadastral surveys, possibly even full city scale. This feature, coupled to output ease of interpretation, gives the methodology wide potential of use by municipal authorities. An automatic, large scale sidewalk fast survey methodology has been proposed by Frackelton et al. (2013), but this 
methodology deals only with pavement issues. We stress that our aim is to evaluate sidewalk performance, not neighborhood walkability or pedestrian level of service, as defined by e.g., Tan et al. (2007), which are different concepts, encompassing things other than just sidewalk infrastructure-related attributes.

This article is organized as follows. In section 2 the methodology is introduced, in the context of a case study of 23 sidewalks in the city of Coimbra, Portugal. It starts by the defining and motivating the criteria set, and proceeds applying ELECTRE TRI to field data and analysing the output. Section 3 summarizes and concludes.

\section{Methodology for assessing sidewalk performance}

The proposed methodology concerns the following problem:

Given a number of sidewalks and respective scores in the criteria under scrutiny, assign each of them to the (previously defined) performance class that best represents its actual performance, e.g. 'unsuitable', 'major repairs required', 'minor repairs required', 'suitable'.

This configures, by definition, a multicriteria problem of the 'sorting (or $\beta$ ) problematic' type (Figueira et al. 2005). The outcome of this classification process can then be fed into statistical representations (frequency tables, histograms), to give municipal decision makers an overview of sidewalk condition, or into a Geographical Information System (GIS), for spatial visualization. The class assignment output type makes subsequent decision making straightforward, allowing the compatibility with economic aspects (e.g. budget constraints), safety requirements, etc. A typical decision would be e.g. 'we shall improve sidewalks that are unsuitable or require major repairs'. Spatial output can also aid decision making: if e.g. most unsuitable sidewalks lie clustered on a particular location in the city, municipal authorities may decide to concentrate on that location first.

\subsection{The criteria set}

Since the proposed methodology aims at subsequent intervention works, the set of criteria to choose from focuses on those that can be intervened by municipal authorities. This leaves aside hard geographic characteristics, such as e.g. slope or road intersections, and socio- 
economic variables, such as adjacent land use, which may contribute for a more/less pleasant walk but are not affected by intervening on the sidewalk alone.

The proposed criteria set is shown in table 1 . Some criteria, too abstract to assess directly, are broken down to more tangible sub-criteria (Wang 2011). These are referred to as "constructed criteria" below (Keeney 2009) and were used in previous literature on infrastructure assessment for measuring of the achievement of an objective for which no natural attribute exists.

\section{(Insert Table 1 about here)}

The above criteria are, in one way or another, all related to factors identified in the literature as influencing walkability of neighborhoods or pedestrian routes (Gallin 2001; Kelly et al. 2011; TRL 2003).

Criteria that cannot be directly evaluated (and some components of constructed criteria) are assessed by visual inspection using a discrete five-values Likert scale, with start set at zero (not one) for all cases, to reflect zeroing of the quantity at hand. Visual inspection is common in engineering when measurements based on rigorous definitions is difficult, time consuming or outright impossible. For recent examples of visual inspection see e.g. (Dirksen et al. 2013) (sewer inspection), (Sadeghi \& Askarinejad 2011) (railway tracks), and (Pellegrino et al. 2011) (bridges). In the context of sidewalks, Likert scales have been used by e.g. Gallin (2001), Jaskiewicz (2000) and TRL (2003). For the present article, the approach of using visual inspection in tandem with Likert scales is justified because the proposed methodology aims at large scale surveys, so quick and easy collecting of individual data is required. Since field measurements are to be done by experts (engineers or seasoned technicians), the accuracy of these surveyors' judgment should, for practical purposes, suffice. Simplicity does not necessarily mean less accuracy; in fact, recent research has shown that excessively detailed survey sheets for visual inspection may lead to less quality of the outcome (van der Steen et al. 2014). 
Finally, the length of all sidewalks/segments also needs to be measured, as it is required to calculate some of the constructed criteria. It may be noted that for purposes of the analysis, each sidewalk section that was considered very heterogeneous was decomposed into multiple homogeneous segments.

Details on the above sidewalk criteria are now given, together with some motivation and details on how to calculate them.

\section{Width}

This is a natural criterion to choose, as sidewalks need to be wide enough to accommodate pedestrians and, the wider they are, the less prone they are to congestion. Also, wide sidewalks make for a more pleasant walk, from an architectonical point of view. It is the service, or effective, width that is considered here, i.e. width useable by pedestrians on a straight line. Width taken e.g. by trees planted along a strip of the sidewalk is not to be accounted for. However, if the linear density of these trees is small enough, the full width can be taken into account. It is up to the surveyor to judge the situation.

\section{Pavement suitability}

Smooth pavement makes walking a pleasant experience, whereas bumpy surfaces can be cumbersome and hazardous to walk through. While some of the negative effect may be mitigated by footwear, sidewalks that perform well in this criterion should provide for a more pleasant and safe experience. Pavement should also provide an adequate amount of friction. Suitability is evaluated by the surveyor on a 0-4 Likert scale with: 0 -unsuitable, 1-poor, 2reasonable, 3-good, 4-very good.

\section{Conservation status}

Bad conservation status leads to irregularities that in turn cause discomfort to pedestrians, may force them to change direction, and can, in extreme cases, lead to accidents. This criterion is evaluated in a 0-4 Likert scale by the surveyor as follows: 0 -unsuitable, 1-poor, 2reasonable, 3-good, 4-very good. When evaluating this criterion, the surveyor should be on the lookout for phenomena such as uneven ground/stub toes $(13+\mathrm{mm}$ tile vertical displacement (PBT 2013)); floor holes; pavement damage/cracks (crack: 13+ mm wide (PBT 
2013)); tilts along the width direction; and root bumps.

\section{Accessibilities}

Sidewalks are accessed via curbs and crossings. Sidewalk curbs should not be too tall and access ramps are needed to cater for disabled people. Four components are considered here: (1) curb height/conservation; (2) crossing visibility (stoplights, vertical signs, visibility of pedestrians and zebras); (3) density of crossings; (4) density of access ramps. Curb condition and visibility are evaluated in a 0-4 scale (0-unsuitable, 1-poor, 2-reasonable, 3-good, 4-very good) whereas densities are evaluated comparing the quotient $Q=n r$. of crossings/sidewalk length (likewise for ramps) to the reference value of 1 crossing (ramp) per $100 \mathrm{~m}\left(Q_{r e f}\right)$ (NZTA 2009). A score of $Q / Q_{r e f}$ is given if $Q<Q_{r e f}$, and 1 otherwise. If a sidewalk has no crossings, scores of visibility and ramps are set to zero. Likewise, if the street is short and quiet enough to be classified as 'not needing crossings' (TECC 1998), a score of 1 is given to these components. Finally, because components (1) (2) are scored 0-4 and components (3) (4) scored $0-1$, the former two should be normalized to 1 prior to doing the final weighted sum.

The final accessibilities score is given by:

$$
\text { Access }=\sum_{i} W A_{i} n_{i} x_{i}
$$

Where:

$$
W A_{i}=\text { weight } \text { of accessibility component } i(i=1, \ldots, 4) \text {. }
$$$$
\left.n_{i}=\text { normalization factor for component } i \text { (respectively } 1 / 4,1 / 4,1,1\right) .
$$

$x_{i}=$ score of accessibility component $i$.

Surveyors should however be critical when assigning final accessibility scores, as situations may arise that call for specialized treatment. Indeed, if a sidewalk without crossings is just shy of, or barely over, $100 \mathrm{~m}$, its score may oscillate between 0 and 1; a sharp score difference for a low de facto difference. In this case surveyors should exercise judgment to decide what would be the more appropriate score (e.g. by looking at the distance to the nearest crossing). The same applies to contiguous sidewalks/segments of less than $100 \mathrm{~m}$ : individually none would require a crossing, but seen as a chain, some crossings may be 
necessary. Surveyors should be on the lookout for situations like the above and judge them appropriately.

\section{Safety from traffic}

Existence of separation between pedestrians and street traffic contributes to the sense of safety. Traffic flow also needs to be taken into account, as quiet/busy streets require less/more separation to give pedestrians the same sense of safety. Some of the factors contributing to this criterion have been identified in a previous work by e.g. Landis et al. (2001). Here a simpler approach is proposed, which requires collecting only buffer zone width and type, and traffic volume. The formula for safety score is:

$$
\text { Safety }=4-(\text { TVol }- \text { Buffer }) \times \theta(\text { TVol }- \text { Buffer })
$$

Where:

$T V o l=$ traffic volume, on a 0-4 scale.

Buffer $=\operatorname{round}\left[\ln \left(1+\right.\right.$ WBuff $\left.\left.\times\left(\sum_{i} f_{i} x_{i}\right)\right)\right]$.

$\theta(x)=$ unit step function; 1 if $x \geq 0,0$ if $x<0$.

WBuff = width of buffer zone.

$f_{i}=$ multiplier factor for buffer type $i .(i=1, \ldots, 4)$

$x_{i}=$ binary variable for existence of buffer type $i$ in buffer zone (cumulative).

The traffic volume is evaluated qualitatively by the surveyor as 0 -none, 1-quiet, 2-normal, 3busy, 4-very busy. The score should reflect not only traffic volume but also vehicle type and speed. Buffer types considered are 1-bike/safety lanes, 2-trees, 3-parking pins, 4-parking lanes (more types can be considered if desired); its $f_{i}$ multipliers usually ranging from 0.5 to 3 , in the appropriate units. For instance for trees a value of $3 \mathrm{~m}^{-1}$ is suggested, as it leads to a Buffer outcome in line with the example of FDT (2009), p.64, where tree barriers have an 1.5-fold impact on separation.

Presence of the $\ln ()$ function follows Landis et al. (2001), which found best field data fit for log-like regression on this criterion. Indeed, it seems logical that be first few meters away from traffic cause a higher impression of safety than the same meters added to a much wider 
sidewalk. Multipliers $f_{i}$ for buffer zone type are also presented by Landis et al. (2001), reflecting the fact that some buffer zones (e.g., trees) provide a higher sense of safety than others. The round() function transforms Buffer values into integers falling into the 0-4 range. This is done to mirror the 0-4 Likert scale in which traffic is evaluated. If the decision maker opts for plugging into this slot more precise, quantitative field traffic volume measurements, then the round() function should be removed from Buffer, so as to have all real numbers on the subtraction TVol - Buffer. Consequently, TVol measurements should be rescaled into a 0-4 continuous scale, to ensure comparability with Buffer.

Because the model of Landis et al. (2001) requires collecting precise and extensive amounts of data, doing so on a large scale is difficult and very time consuming. This is why the simple model above is proposed instead, since it only requires data that is very easy and quick to collect, even on a large scale. Municipal authorities have in fact detected the same problem and devised ways to simplify Landis' model (see e.g. FDT 2009). Consolidating several factors into one single 'buffer separation function' (as is done here) is recommended by that reference. The scheme proposed here is slightly more complex than that of the former reference because it tries to capture Landis' logarithmic dependence on separation, but remains straightforward enough to still allow for quick, large-scale data collecting.

\section{Lightning}

This criterion becomes critical for pedestrians at night time. Nearly all urban sidewalks are lit, but insufficiently lit strips cause a sense of insecurity. Pedestrians may refrain from walking the street in those cases. Lightning is evaluated in a 0-4 scale with: 0 -unsuitable, 1poor, 2-reasonable, 3-good, 4-very good.

\section{Obstacle density}

Sidewalks become unpleasant if cluttered with (vertical) obstacles such as outdoor advertising, incorrectly positioned waste/recycle bins and urban furniture, water outlets, trees, protruding parked vehicles, etc. This criterion is scored 0-4 as follows: 0-none, 1-low, 2tolerable, 3-considerable, 4-cumbersome walk.

\section{Walking environment}


This refers to the level to which a sidewalk is endowed with useful urban furniture, such as rubbish bins and rest places, and vegetation that can provide a soothing atmosphere and/or shade. It does not refer to the architectonical and social aspects of the surroundings, as intervening at the sidewalk level does not change these. The score is obtained similarly to accessibilities, with vegetation expressed in a 0-4 scale, and bin/rest place densities defined relative to a reference value, which can be e.g. the best score in the dataset. Thus $Q=n r$. of bins/sidewalk length (likewise for rest places) and score equal to $Q / Q_{\text {best. }}$. Normalization of scales necessary.)

$$
\text { WalkEnv }=\sum_{i} W E_{i} n_{i} x_{i}
$$

Where:

$W E_{i}=$ weight of walking environment component $i$.

$n_{i}=$ normalization factor for component $i$. (1/4 for vegetation, 1 for rest place/bins)

$x_{i}=$ score of component $i$. ( 1 for best performing sidewalk)

\section{Pedestrian density}

This is defined as the HCM level of service (Board, 2000). The A-F ratings shown in section 9 of the checklist for assessment of sidewalk performance (see below) are transformed into a 0-5 benefit scale, where $A=5$. While not directly intervenable, it can be changed via sidewalk width. It is important to consider it because a sidewalk may be wide, but not wide enough to accommodate for large pedestrian peak flows, in which case it will be underperforming (Polus et al. 1983). The HCM level of service definition is precise but rather difficult to measure accurately. Hence, its evaluation is done qualitatively by the surveying expert, based on the HCM text description of service levels. While not completely accurate, it should not be too far off more precise, but time-consuming, measurements.

In the case study a checklist was used to register field data. The checklist form is shown in the supplementary material.

\subsection{Classifying sidewalk performance - ELECTRE TRI}

The ELECTRE TRI multicriteria method is a widely used classifying method that mimics 
characteristics of human judgment. It was conceived to place actions, objects or items into sorted predefined classes $\left(\mathrm{C}_{1}, \mathrm{C}_{2}, \ldots \mathrm{C}_{k}\right)$, considering multiple criteria, with each class delimited by a lower and an upper profile (Figueira et al. 2005). ELECTRE family methods have been used in several other ranking and classification problems related to engineering and building performance (see e.g. Kabir et al. 2014; Natividade-Jesus et al. 2013; Rogers \& Bruen 2000; Rogers et al. 2013 and references therein). Conceptual and technical details on the ELECTRE methods are presented in Roy (1991).

The main features of ELECTRE TRI, which are relevant in the context of our study, can be enumerated as follows:

- Under ELECTRE TRI, results are expressed as "assign" or "not assign" a sidewalk to a performance class. In defining the limits of these classes, the user can select either real sidewalks as reference or, as was done in the case study (see below), define hypothetical sidewalks with adequate values for the criteria. Real sidewalks are then assigned to one of those classes.

- Its intrinsic non-compensatory nature, that is, a very low performance on a given evaluation aspect (criterion) cannot be compensated by good scores on other criteria. This overcomes the inconveniences of the weighted sums frequently used to obtain final scores in decision problems.

- It accommodates in a natural way the imprecision and uncertainty inherent to human decision processes by using indifference, preference and veto thresholds. The introduction of these thresholds provides a technically sound way to deal with the uncertainties stemming from different sources, not just regarding preferences, but also lack of data precision.

- ELECTRE TRI classifies the selected alternatives according to the type of assignment, pessimistic or optimistic, depending the degree of exigency of the decision maker (Mousseau et al. 2001).

Given these characteristics, ELECTRE TRI seems to be particularly adequate for the study of the sidewalk performance. Also, because the output of ELECTRE TRI is clear to interpret, it 
is possible to devise maintenance strategies directly from it. As mentioned in the beginning of this section, usually (but not necessarily) these decisions take the form of intervening on the sidewalks in worst condition and, budget constraints allowing it, intervening in the next-toworst sidewalks, and so forth. The case study below exemplifies some of the decision-making possibilities permitted by the proposed approach.

\subsection{Case study}

A total of 23 sidewalks in the city of Coimbra, Portugal, were selected from a varied range of locations for a case study. Data was collected in the field, except for sidewalk length, which was derived on desktop, from Google Earth GIS tools. Two experts carried out the survey independently, and final criteria scores were averaged out when a consensus was not reached. Having two surveyors on the field is a procedure recommended by (TRL 2003).

Constructed criteria weights chosen were $W A_{i}=0.25 \forall i ; W E_{i}=(0.4,0.3,0.3)$, and other parameters were $f_{1}=0.5$ (void space/bike lane); $f_{2}=3$ (trees); $f_{3}=f_{4}=1.5$ (park pins, park lane) and $Q_{\text {best }}$ was taken as reference for bin and rest place density. The data yielded the performance matrix shown in table 2 .

(Insert Table 2 about here)

Prior to running ELECTRE TRI, reference alternatives (sidewalks) corresponding to lower and upper profiles of each predefined class must be defined, as well as other parameters such as indifference, preference and veto thresholds, and criteria weights. For the case study three reference sidewalks (A1, A2, A3) were defined (this leads to four classes) with criterion values (Figure 1)

$$
\begin{aligned}
& \mathrm{A} 1=(1.2,1,1,0.3,1,1,3,0.3,1) \\
& \mathrm{A} 2=(1.5,2,2,0.5,2,2,2,0.5,2) \\
& \mathrm{A} 3=(2.0,3,3,0.7,3,3,1,0.7,4)
\end{aligned}
$$

Real sidewalks are to be compared against these reference sidewalks, sorted from worst to best profiles as A1, A2, A3, leading to the delimitation of a corresponding sorted set of four 
classes, as represented graphically in Figure 1. Width references were set according to the guidelines of the Portuguese Decree-Law 163/2006 (INCM 2006), which defines 1,5 m as 'acceptable' and 2,0 $\mathrm{m}$ as 'desirable' sidewalk widths, and 1,2 $\mathrm{m}$ as 'desirable' for narrower streets where it is impossible to achieve 1,5 m widths. Reference values for other criteria were defined so as to have better resolution in the central zone, which is where criteria values most often sit in practice.

For the purpose of our case study two sets of criterion weights, obtained by expert agreement, were adopted, the first focusing on ease and comfort of walking (W1), the second on pedestrian safety (W2):

\section{(Insert Figure 1 about here)}

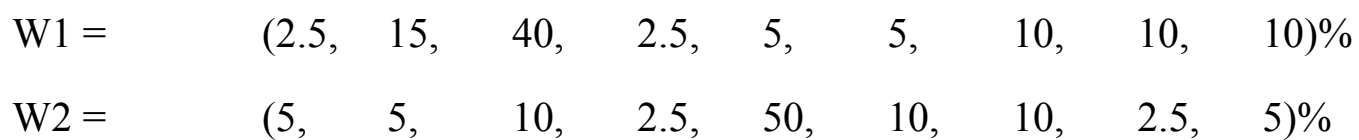

Finally, indifference, preference and veto thresholds, standard parameters required by ELECTRE TRI (see e.g. Mousseau et al. 2001) were set to

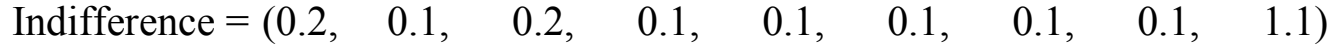

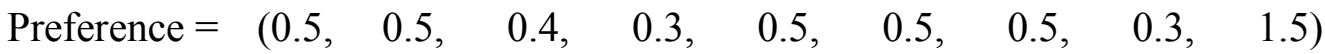

$$
\begin{aligned}
& \text { Veto }=\quad(1.5, \quad 1.5, \quad 0.5, \quad 0.5, \quad 0.9, \quad 1.1, \quad 1.1, \quad 0.5, \quad 2.5)
\end{aligned}
$$

The thresholds for Likert scale criteria were chosen to be consistent with the scale itself, in the sense that one cannot distinguish criteria within the same level, can objectively distinguish between two adjacent levels (hence, prefer one to the other), and put a veto on levels that are two or more away. For pedestrian density, which has a 6-level scale, indifference between adjacent levels was considered, with preference and veto starting from two and three levels away, respectively. A stricter veto threshold was put for the conservation status and safety from traffic, as these are the more critical performance attributes.

The results with pessimistic assignment are, for both sets of weights, depicted in Figure 2. 
The outcome is very similar for both sets of weights, with difference in only two sidewalks changing class (\#19, \#21). Further tests performed showed robustness of the results against large weights changes, which is in fact a plus-value, as high fluctuations require more consideration by the decision maker.

\subsection{Maintenance planning based on case study output}

The class-placement output shows that some sidewalks fall in the lowest performance class, and are thus in need of some sort of intervention. Closer inspection reveals that this is mainly due to low scores in the safety and conservation status attributes, which prevent progression to the next class. The simplest, first stage maintenance decision that can be drawn from this analysis is to deal straight away with the more urgent cases, providing for pavement repairs where necessary and creating a buffer zone good enough to have unsafe sidewalks progress at least one class up. A follow-up decision would be, in a second stage, to devise a mid-term plan for intervening sidewalks that fall into class 2. Naturally, if budget constraints allow it, doing these two stages at the same time (i.e. improving all sidewalks to class 3 or better) might produce some scale economy. It is up to the decision maker to check whether she/he can afford this. The proposed classifying methodology can be helpful for this as well, since it can be rerun with new criteria values, to check whether a particular intervention scheme is good enough for the desired class upgrades.

As the case study shows, the methodology suggests, readily and naturally, clear and effective maintenance strategies to municipal authorities, which can provide equity for users while keeping within budget constraints. These can be further refined using the statistical and/or GIS representations, suggested in the beginning of section 2. Such strategies are harder to derive from other sidewalk and walkability assessment tools in the literature, since these usually aim instead at evaluating more abstract performance indicators, making it more difficult to ascertain the best course of action for the sidewalk component. The proposed methodology, which is more practical, has thus potential to be widely used by municipal 
authorities to determine the most effective sidewalk maintenance actions.

\subsection{Summing up the procedure}

The proposed methodology can be summarized in the schematic representation of Figure 3. It should be noticed that one of the basic distinguishing features of multicriteria decisionmaking is the iterative and interactive nature of the modeling procedure, where two phases alternate: computer calculation, and active dialogue involving the decision maker, who analyses and tests outputs in different setups. After a certain number of iterations, a final prescription is derived from the procedures (see e.g. Vanderpooten 1989). In this way, different preference parameters, such as weights and thresholds, may be tested in order to construct the final classification and proceed to the decision phase.

\section{(Insert Figure 3 about here)}

\section{Conclusions}

In this article a methodology for assessment of sidewalk performance, based on multicriteria classifying methods, was presented. The methodology was designed to be widely applicable by municipal decision makers, regardless of city location and size, and aiming at facilitating subsequent agency decision regarding maintenance strategy development and deployment. Simplicity and ease of data collecting is another key feature of the present methodology, which ensures its wide applicability. The use of scientific multicriteria methods fills a void in the literature, which has so far approached the subject with simpler models. The previous approaches also often mix other walkability elements into the analysis, which are not directly or easily intervenable by municipal authorities, making it more difficult to judge the best course of action for sidewalk maintenance alone. Finally, the methodology's output is simple and visually appealing, making it easy for the decision maker to have an overall view of the current sidewalks network status and evaluate opportunities for improvements.

The proposed methodology is thus a widely applicable, turnkey solution for a practical urban engineering need. It is also simple to parameterize by surveyors and decision makers (e.g. the number of performance classes and sets of weights/thresholds suitable to the case at hand). It 
has thus excellent potential for use by municipal authorities in determining the most effective maintenance actions to improve sidewalk infrastructures, given limited resources.

\section{Acknowledgements}

This work was partially supported by the Portuguese Foundation for Science and Technology under project grant UID/MULTI/00308/2013; and the initiative Energy for Sustainability of the University of Coimbra, supported by project Energy and Mobility for Sustainable Regions (EMSURE), under grant - CENTRO-07-0224-FEDER-002004.

\section{Supplemental Data}

The proposed checklist form for sidewalks survey is available online in the ASCE Library (ascelibrary.org).

\section{References}

Abley, S. (2005). Walkability Scoping Paper. Land Transport New Zealand, Christchurch, New Zealand.

Angulo, E., Castillo, E., García-Ródenas, R., and Sánchez-Vizcaíno, J. (2012). “Determining Highway Corridors." J. Transp. Eng., 138(5), 557-570. 10.1061/(ASCE)TE.19435436.0000361

Bai, Q., Labi, S., and Sinha, K. (2012). "Trade-Off Analysis for Multiobjective Optimization in Transportation Asset Management by Generating Pareto Frontiers Using Extreme Points Nondominated Sorting Genetic Algorithm II.” J. Transp. Eng., 138(6), 798-808. 10.1061/(ASCE)TE.1943-5436.0000369, 798-808.

Bana-e-Costa, C.A., Oliveira, C.S., and Vieira, V. (2008). "Prioritization of bridges and tunnels in earthquake risk mitigation using multicriteria decision analysis: Application to Lisbon." Omega, 36(3), 442-450. DOI: 10.1016/j.omega.2006.05.008

Buehler, R., and Pucher, J. (2012). "Walking and cycling in Western Europe and the United 
States: trends, policies, and lessons.” TR News, 280, 34-42. Transportation Research Board, Washington DC.

Cerin, E., Saelens, B.E., Sallis, J.F., and Frank, L.D. (2006). "Neighborhood Environment Walkability Scale: validity and development of a short form." Med. Sci. Sports Exerc. 38(9), 1682-1691. DOI: 10.1249/01.mss.0000227639.83607.4d

Cervero, R., and Radisch, C. (1996). "Travel choices in pedestrian versus automobile oriented neighborhoods." Transport Policy, 3(3), 127-141. DOI: 10.1016/0967070X(96)00016-9

Clifton, K., Smith, A., and Rodriguez, D. (2007). "The Development and Testing of an Audit for the Pedestrian Environment." Landscape Urban Plann., 80(1-2), 95-110. DOI: 10.1016/j.landurbplan.2006.06.008

Current, J., and Min, H. (1986). "Multiobjective Design of Transportation Networks: Taxonomy and Annotation.” Eur. J. Oper. Res., 26(2), 187-201. DOI: 10.1016/03772217(86)90180-3

Current, J., and Marsh, M. (1993). "Multiobjective transportation network design and routing problems: Taxonomy and annotation." Eur. J. Oper. Res., 65(1), 4-19. DOI: $10.1016 / 0377-2217(93) 90140-\mathrm{I}$

Dirksen, J., Clemens, F.H.L.R., Korving, H., Cherqui, F., Le Gauffre, P., Ertl, T., Plihal, H., Müller, K., and Snaterse, C.T.M. (2013). "The consistency of visual sewer inspection data." Struct. Infrastruct. Eng., 9(3), 214-228. DOI: 10.1080/15732479.2010.541265

Ewing, R., Handy, S., Brownson, R.C., Clemente, O., and Winston, E. (2006). "Identifying and measuring urban design qualities related to walkability." J. Phys. Act. Health, 3(s1), 223-240. DOI: 10.1123/jpah.3.s1.s223

Ewing, R., and Handy, S. (2009). "Measuring the Unmeasurable: Urban Design Qualities Related to Walkability." Journal of Urban Design, 14(1), 65-84. DOI: $10.1080 / 13574800802451155$

FDT. (2009). Quality/Level of Service Handbook. State of Florida Department of 
Transportation, Tallahassee, FL, USA.

Figueira, J., Mousseau, V., and Roy, B. (2005). "ELECTRE methods." Multiple Criteria Decision Analysis: State of the Art Surveys, Springer, Boston, USA, Part III, Chaper 4, pp. 133-153. ISBN: 978-0-387-23067-2

Frackelton, A., Grossman, A., Palinginis, E., Castrillon, F., Elango, V., and Guensler, R. (2013). "Measuring Walkability: Development of an Automated Sidewalk Quality Assessment Tool." Suburban Sustainability, 1(1), art. no. 4. DOI: 10.5038/21640866.1.1.4

Frank, L.D., Sallis, J.F., Conway, T.L., Chapman, J.E., Saelens, B.E., and Bachman, W. (2006). "Many pathways from land use to health: associations between neighborhood walkability and active transportation, body mass index, and air quality." J. Am. Plann. Assoc., 72(1), 75-87. DOI: 10.1080/01944360608976725

Gallin, N. (2001). "Quantifying pedestrian friendliness--guidelines for assessing pedestrian level of service." Road \& Transport Research, 10(1), 47-55

Gase, L.N., Barragan, N.C., Simon, P.A., Jackson, R.J., and Kuo, T. (2015). "Public awareness of and support for infrastructure changes designed to increase walking and biking in Los Angeles County." Prev. Med., 72, 70-75. DOI: 10.1016/j.ypmed.2014.12.033

Gharaibeh, N.G., and Lindholm, D.B. (2014). "A condition assessment method for roadside assets." Struct. Infrastruct. Eng., 10(3), 409-418. DOI: 10.1080/15732479.2012.757330

Gosse, C.A., Smith, B.L., and Clarens, A.F. (2012). "Environmentally preferable pavement management systems." J. Infrastruct. Syst. 19(3), 315-325. 10.1061/(ASCE)IS.1943555X.0000118

INCM (Imprensa Nacional Casa da Moeda [Portuguese Mint Press]). (2006). "Decreto-Lei 163/2006. Regime da Acessibilidade aos Edifícios e Estabelecimentos que Recebem Público, Via Pública e Edifícios Habitacionais [Portuguese Decree-Law regulating accessibility to public buildings, public streets and housing]". Diário da República, I Série, 152 (8 de Agosto), pp. 5670-5689. 
Jaskiewicz, F. (2000). "Pedestrian level of service based on trip quality." Proc. Urban Street Symposium Conf., Transportation Research Board, Dallas, Texas, Vol. G, 1-14.

Kabir, G., Sadiq, R., and Tesfamariam, S. (2014). "A review of multi-criteria decisionmaking methods for infrastructure management." Struct. Infrastruct. Eng., 10(9), 11761210. DOI: $10.1080 / 15732479.2013 .795978$

Keeney, R.L. (2009). Value-focused thinking: A path to creative decisionmaking. Harvard University Press, Cambridge, Massachussets, USA. ISBN 978-0-674-93198-5

Kelly, C.E., Tight, M.R., Hodgson, F.C., and Page, M.W. (2011). "A comparison of three methods for assessing the walkability of the pedestrian environment." J. Transp. Geogr., 19(6), 1500-1508. DOI: 10.1016/j.jtrangeo.2010.08.001

Khisty, C.J. (1994). "Evaluation of pedestrian facilities: beyond the level-of-service concept." Transp. Res. Rec., 1438, 45-50.

Landis, B., Vattikuti, V., Ottenberg, R., McLeod, D., and Guttenplan, M. (2001). Modeling the roadside walking environment: pedestrian level of service. Transp. Res. Rec., 1773, 82-88. DOI: $10.3141 / 1773-10$

Lu, P., and Tolliver, D. (2013). "Multiobjective Pavement-Preservation Decision Making with Simulated Constraint Boundary Programming." J. Transp. Eng., 10.1061/(ASCE)TE.1943-5436.0000573, 880-888.

Manaugh, K., and El-Geneidy, A. (2011). "Validating walkability indices: How do different households respond to the walkability of their neighborhood." Transp. Res. D, 16(4), 309315. DOI: $10.1016 / j . \operatorname{trd} .2011 .01 .009$

Millward, H., Spinney, J., and Scott, D. (2013). "Active-transport walking behavior: destinations, durations, distances." J. Transp. Geogr., 28, 101-110. DOI: 10.1016/j.jtrangeo.2012.11.012

Mishalani, R.G., and McCord, M.R. (2006). "Infrastructure Condition Assessment, Deterioration Modeling, and Maintenance Decision Making: Methodological Advances and Practical Considerations." J. Infrastruct. Syst., 3(145), 145-146. 
Mishalani, R.G., and McCord, M.R. (2008). "Infrastructure Condition Assessment, Deterioration Modeling, and Maintenance Decision-Making: New Contributions for Improved Management." J. Infrastruct. Syst., 2(115), 115-116. 10.1061/(ASCE)10760342(2008)14

Morais, P., and Camanho, A.S. (2011). "Evaluation of performance of European cities with the aim to promote quality of life improvements." Omega, 39(4), 398-409. DOI: 10.1016/j.omega.2010.09.003

Moura, F., Cambra P., and Gonçalves, A. (2014). "IAAPE - Pedestrian accessibility and attractiveness assessment tool when planning for walkability." Bridging the Implementation Gap of Accessibility Instruments and Planning Support Systems, 7th Annual Conf., CITTA - Centro de Investigação do Território, Transportes e Ambiente [Resarch Center for Territory, Transport and Environment]. Weblink: http://www.iaape.org/CITTA\%20Paper\%20-\%20IAAPE_FM_PC_AG.pdf

Mousseau, V., Figueira, J., and Naux, J.-Ph. (2001). "Using assignment examples to infer weights for ELECTRE TRI method: Some experimental results." Eur. J. Oper. Res., 130(2), 263-275. DOI: 10.1016/S0377-2217(00)00041-2

Mulliner, E., Smallbone, K., and Maliene, V. (2013). “An assessment of sustainable housing affordability using a multiple criteria decision making method." Omega, 41(2), 270-279. DOI: 10.1016/j.omega.2012.05.002

Natividade-Jesus, E., Coutinho-Rodrigues, J., and Tralhao, L. (2013). "Housing evaluation with web-SDSS in urban regeneration actions." Proc. Inst. Civ. Eng. Munic. Eng., 166(3), 194-207. DOI: $10.1680 /$ muen. 12.00022

NZTA (New Zeland Transport Agency). (2009). Pedestrian planning and design guide. New Zeland Transport Agency, Victoria, New Zeland. ISBN 978-0-478-35229-0.

Park, S. (2008). Defining, Measuring, and Evaluating Path Walkability, and Testing Its Impacts on Transit Users' Mode Choice and Walking Distance to the Station. $\mathrm{PhD}$ Thesis, UCTC (University of California Transportation Center). UMI Microform 
3331760, ProQuest LLC, Ann Arbor, Michigan, USA.

PBT (Portland Bureau of Transportation). (2013). Sidewalk Repair Manual. City of Portland Bureau of Transportation, Portland, Oregon, USA.

Pellegrino, C., Pipinato A., and Modena, C. (2011). "A simplified management procedure for bridge network maintenance." Struct. Infrastruct. Eng., 7(5), 341-351. DOI: $10.1080 / 15732470802659084$

Polus, A., Schofer J.L., and Ushpiz, A. (1983). "Pedestrian Flow and Level of Service.” J. Transp. Eng., 1(46), 46-56. 10.1061/(ASCE)0733-947X(1983)109

Pucher, J., and Buehler, R. (2010). "Walking and Cycling for Healthy Cities." Built Environment, 36(4), 391-414. DOI: 10.2148/benv.36.4.391

Rahul, T.M., and Verma, A. (2014). "A study of acceptable trip distances using walking and cycling in Bangalore." $J . \quad$ Transp. Geogr., 38, 106-113. DOI: $10.1016 /$ j.jtrangeo.2014.05.011

Rodrigues, D., Neiva, C., and Ramos, R. (2012). "A multicriteria model for evaluating conformity of travelling conditions for pedestrians with mobility constraints." WSEAS Transactions on Environment and Development, 3(8), 71-83.

Rogers, M., and Bruen, M. (2000). "Using ELECTRE III to Choose Route for Dublin Port Motorway." J. Transp. Eng., 4(313), 313-323. 10.1061/(ASCE)0733-947X(2000)126

Rogers, M.G., Bruen, M., and Maystre, L.-Y. (2013). Electre and Decision Support: Methods and Applications in Engineering and Infrastructure Investment. Springer Science \& Business Media LLC, New York, USA.

Roy, B. (1991). "The outranking approach and the foundations of electre methods." Theor. Decis., 31(1), 49-73. DOI: 10.1007/BF00134132

Sadeghi, J.M., and Askarinejad, H. (2011). "Development of track condition assessment model based on visual inspection." Struct. Infrastruct. Eng., 7(12), 895-905. DOI: $10.1080 / 15732470903194676$

Sadek, S., Bedran, M., and Kaysi, I. (1999). "GIS platform for multicriteria evaluation of 
route alignments." J. Transp. Eng., 2(144), 144-151. 10.1061/(ASCE)0733947X(1999)125

Saelens, B.E., Sallis, J.F., Black, J.B., and Chen, D. (2003). "Neighborhood-Based Differences in Physical Activity: An Environment Scale Evaluation.” Am. J. Public. Health, 93(9), 1552-1558. DOI: 10.2105/AJPH.93.9.1552

Sayyadi, G., and Awasthi, A. (2013). "AHP-Based Approach for Location Planning of Pedestrian Zones: Application in Montréal, Canada.", 139(2) , 239-246. J. Transp. Eng., 10.1061/(ASCE)TE.1943-5436.0000493

Schofer, J.L., Evans, L., Freeman, M.P., Galehouse, L.L., Madanat, S., Maher, A., McNeil, S., Myers, J.J., Peskin, R.L., and Wlaschin, B. (2010). "Research agenda for transportation infrastructure preservation and renewal: Conference report." J. Infrastruct. Syst., 10.1061/(ASCE)IS.1943-555X.0000038, 228-230.

Seneviratne, P.N. (1985). “Acceptable Walking Distances in Central Areas.” J. Transp. Eng., 111(4), 365-376. 10.1061/(ASCE)0733-947X(1985)111

Tan, D., Wang, W., Lu, J., and Bian, Y. (2007). "Research on Methods of Assessing Pedestrian Level of Service for Sidewalk." Journal of Transportation Systems Engineering and Information Technology, 7(5), 74-79. DOI: 10.1016/S15706672(07)60041-5

TECC (Traffic Engineering Council Committee). (1998). Design and Safety of Pedestrian Facilities. Institute of Transportation Engineers, Traffic Engineering Council Committee, Washington DC, USA.

TRB (Transportation Research Board). Highway Capacity Manual. National Academy of Sciences, Washington DC, USA. ISBN: 0-309-06681-6.

TRL (Transportation Research Laboratory). (2003). Pedestrian Environment Review System. Transport Research Laboratory, Crowthorne, UK.

van der Steen, A.J., Dirksen J., and Clemens, F.H.L.R. (2014). "Visual sewer inspection: detail of coding system versus data quality." Struct. Infrastruct. Eng., 10(11), 1385-1393. 
645

646

647

648

649

650

651

652

653

654

Vanderpooten, D. (1989). “The interactive approach in MCDA: A technical framework and some basic conceptions." Math. Comput. Modell., 12(10-11), 1213-1220. DOI: $10.1016 / 0895-7177(89) 90363-4$

Wang, N. (2011). "Multi-criteria decision-making model for whole life costing design." Struct. Infrastruct. Eng., 7(6), 441-452. DOI: 10.1080/15732470802670875

Woodcock, J., Banister, D., Edwards, P., Prentice, A.M., and Roberts, I. (2007). "Energy and health 3 - Energy and transport." Lancet, 9592, 1078-1088. DOI: 10.1016/S01406736(07)61254-9

Yu, W. (1992). ELECTRE TRI: Aspects méthodologiques et manuel d'utilisation. Document du LAMSADE, 74, Université de Paris-Dauphine, Paris, France. 
TABLE 1

\begin{tabular}{|c|c|c|c|c|}
\hline Criterion & Description & Type & Scale & Scale type \\
\hline 1. Width & Sidewalk average width & Benefit & metres & continuous \\
\hline $\begin{array}{l}\text { 2. Pavement } \\
\text { Suitability }\end{array}$ & $\begin{array}{l}\text { Suitability of pavement type for } \\
\text { walking }\end{array}$ & Benefit & $\begin{array}{l}\text { 0-4 (unsuitable, poor, reasonable, } \\
\text { good, very good) }\end{array}$ & discrete \\
\hline $\begin{array}{l}\text { 3. Conservation } \\
\text { status }\end{array}$ & Floor damage, path irregularities & Benefit & $\begin{array}{l}\text { 0-4 (unsuitable, poor, reasonable, } \\
\text { good, very good) }\end{array}$ & discrete \\
\hline 4. Accessibilities & $\begin{array}{l}\text { Connectivity between sidewalk } \\
\text { segments, sidewalk access }\end{array}$ & Benefit & $0-1$ constructed criterion & continuous \\
\hline $\begin{array}{l}\text { 5. Safety from } \\
\text { traffic }\end{array}$ & $\begin{array}{l}\text { Separation between pedestrians } \\
\text { and traffic }\end{array}$ & Benefit & $0-4$ constructed criterion & discrete \\
\hline 6. Lightning & $\begin{array}{l}\text { Existence of good lightning } \\
\text { conditions }\end{array}$ & Benefit & $\begin{array}{l}\text { 0-4 (unsuitable, poor, reasonable, } \\
\text { good, very good) }\end{array}$ & discrete \\
\hline $\begin{array}{l}\text { 7. Obstacle } \\
\text { density }\end{array}$ & $\begin{array}{l}\text { Presence of vertical obstacles } \\
\text { throughout the sidewalk }\end{array}$ & Cost & $\begin{array}{l}\text { 0-4 (none, low, tolerable, } \\
\text { considerable, cumbersome walk) }\end{array}$ & discrete \\
\hline $\begin{array}{l}\text { 8. Walking } \\
\text { environment }\end{array}$ & $\begin{array}{l}\text { Conditions for a pleasant walk; } \\
\text { vegetation, urban furniture }\end{array}$ & Benefit & $0-1$ constructed criterion & continuous \\
\hline $\begin{array}{l}\text { 9. Pedestrian } \\
\text { density }\end{array}$ & $\begin{array}{l}\text { Density of people using the } \\
\text { sidewalk at peak hour }\end{array}$ & Benefit & $\begin{array}{l}\text { HCM level of service (A to F } \\
\text { scale, transformed to } 0-5)\end{array}$ & discrete \\
\hline
\end{tabular}


TABLE 2

\begin{tabular}{|c|c|c|c|c|c|c|c|c|c|}
\hline $\begin{array}{c}\text { Sidewalk } \\
\#\end{array}$ & Width & $\begin{array}{l}\text { Pavement } \\
\text { suitability }\end{array}$ & $\begin{array}{c}\text { Conservation } \\
\text { status }\end{array}$ & Accessibilities & $\begin{array}{c}\text { Safety } \\
\text { from } \\
\text { traffic } \\
\end{array}$ & Lightning & $\begin{array}{r}\text { Obstacle } \\
\text { density }\end{array}$ & $\begin{array}{c}\text { Walking } \\
\text { environment }\end{array}$ & $\begin{array}{c}\text { Pedestrian } \\
\text { density }\end{array}$ \\
\hline 1 & 1.9 & 1.5 & 3 & 0.813 & 1 & 1 & 3 & 1 & 4 \\
\hline 2 & 2 & 2 & 3.5 & 0.875 & 1 & 2 & 1 & 0 & 5 \\
\hline 3 & 1.8 & 2 & 3.5 & 0.188 & 1 & 2 & 1.5 & 0 & 5 \\
\hline 4 & 2.3 & 2 & 3.5 & 0.969 & 1 & 2 & 2 & 0.177 & 5 \\
\hline 5 & 3 & 3 & 3.5 & 0.859 & 0 & 2 & 2 & 0.128 & 2.5 \\
\hline 6 & 1 & 3 & 4 & 0.938 & 0 & 2.5 & 0.5 & 0.116 & 5 \\
\hline 7 & 1.5 & 3 & 4 & 0.746 & 1 & 2 & 1 & 0.491 & 5 \\
\hline 8 & 4.1 & 3 & 2.5 & 0.813 & 1 & 2 & 1 & 0.319 & 4.5 \\
\hline 9 & 2.5 & 3 & 4 & 0.471 & 3 & 2 & 1.5 & 0.116 & 5 \\
\hline 10 & 1.05 & 2.5 & 2.5 & 0.405 & 2 & 1.5 & 0 & 0 & 4 \\
\hline 11 & 2.5 & 3 & 3.5 & 0.625 & 3 & 2 & 1 & 0 & 4 \\
\hline 12 & 2.9 & 3 & 3.5 & 0.156 & 3 & 2 & 0 & 0 & 5 \\
\hline 13 & 4.2 & 2.5 & 1.5 & 0.125 & 3 & 1.5 & 0 & 0.324 & 5 \\
\hline 14 & 2.3 & 3 & 2 & 0.458 & 4 & 1 & 0 & 0.582 & 5 \\
\hline 15 & 2.1 & 3 & 3.5 & 0.656 & 4 & 2 & 1 & 0.4 & 5 \\
\hline 16 & 1 & 2.5 & 3 & 0.656 & 2.5 & 2 & 1.5 & 0.464 & 4.5 \\
\hline 17 & 3.2 & 1 & 0 & 0 & 3.5 & 2 & 0.5 & 0.374 & 5 \\
\hline 18 & 4.25 & 3 & 3 & 0.583 & 2.5 & 3 & 1 & 0.302 & 5 \\
\hline 19 & 1.9 & 3.5 & 3 & 0.688 & 0 & 1.5 & 0 & 0.350 & 4.5 \\
\hline 20 & 1.35 & 3 & 3 & 0.930 & 0.5 & 2 & 1.5 & 0.096 & 5 \\
\hline 21 & 4.5 & 3 & 2 & 0.489 & 3 & 1.5 & 1 & 0.212 & 5 \\
\hline 22 & 2.6 & 2 & 0.5 & 0.816 & 4 & 2 & 3.5 & 0.310 & 5 \\
\hline 23 & 2.3 & 3 & 2.5 & 0.844 & 3.5 & 1.5 & 2 & 0.3 & 5 \\
\hline
\end{tabular}


Click here to download Figure Fig_1-Sidewalk_classes_ref_profiles.pdf $\underline{\underline{\boldsymbol{}}}$

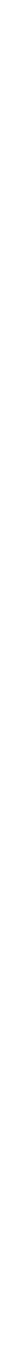




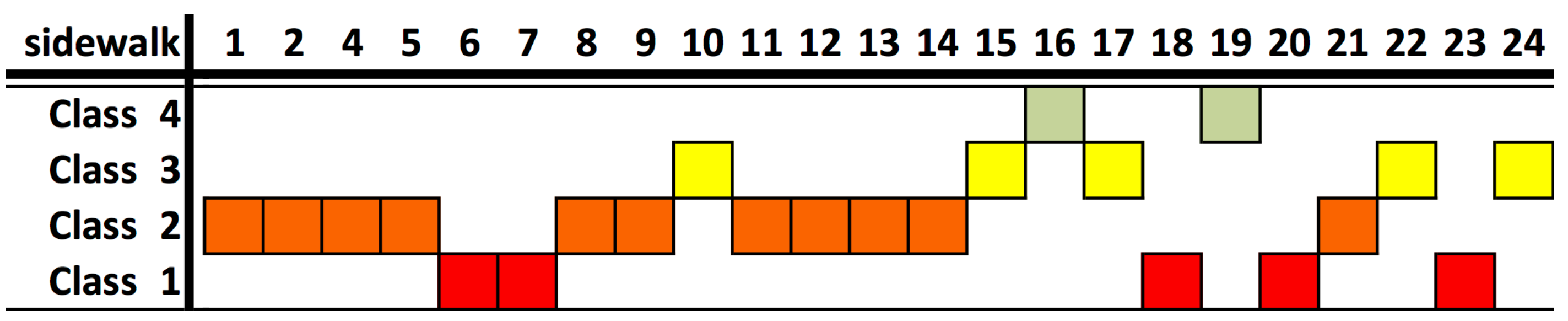

(Comfort)

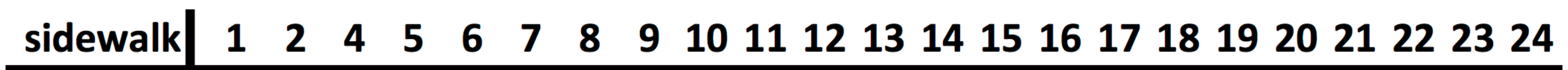

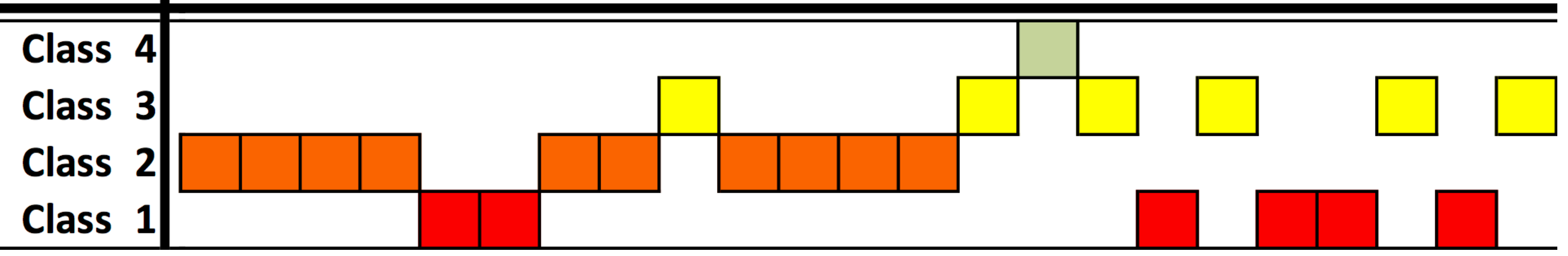

(Safety) 


\section{Design survey}

Delimit survey area

Plan survey routes

Demarcate sidewalk segmentation

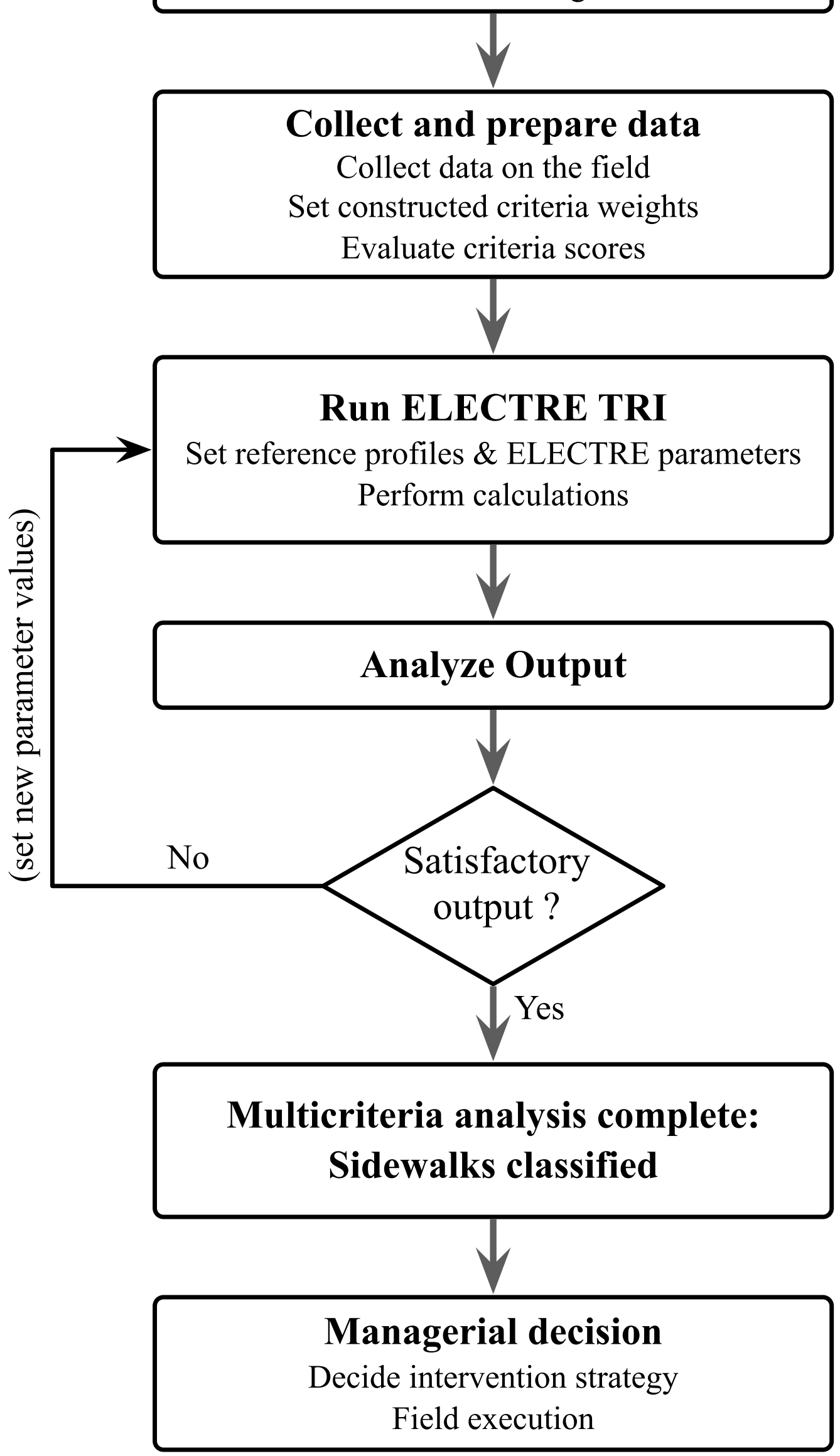




\section{FIGURES}

Fig. 1. Sidewalk classes delimited by reference profiles A1, A2, A3.

Fig. 2. Results of sidewalk multicriteria classification by ELECTRE TRI.

Fig. 3. Schematic representation of the procedure.

\section{TABLES}

Table 1. Criteria for evaluating sidewalk performance.

Table 2. Performance matrix. 
Checklist_form_sidewalk_survey

Click here to access/download Supplemental Data File Checklist_form_sidewalk_survey.pdf 


\section{ASCE Authorship, Originality, and Copyright Transfer Agreement}

Publication Title: Joumal of Infrastructure Systems

Manascript Tule: Multicriteria methodology for sidewalk infrastructure assessment and maintenance planning

Author(s) - Names, postal addresses, and e-mail addresses of all aathors

- Nuno Sousa - Department of Science and Technologies, Open University, Paiácio Ceia, A Escola Politécnica

141-147, 1269-001 Lisboa, Portugal - nscusa suabs

- Joba Coutinho-flodrigues - Department of Clvil Enpineering, Faculty of Sciencess and Technology, Rua Luis Rels

Santos - Polo II, 3030-78B Coimbra, PORTUGAL - coutinhedo dec.uc. ot

- Eduardo Natividade-Jesus - Department of Civil Engineering, Polylechnic Institute of Coimbra, Rua Pedro Nunes,

Quinta da Nora - 3030-199 COIMBRA, Portugal - ednativisisisec,pt

\section{Authorship Responsibility}

To protect the integrity of authorship, only people who have significantly contributed to the research or project and manuscript preparation shal be listed as coauthors. The corresponding author attests to the fact that anyone named as a coauthor has seen the final versicn of the manuscript and has agreed to its submission for publication. Deceased persons who meet the criteria for coauthcrship shall be included, with a foctnote reporting date of death. No fictious name shall be given as an author $\propto$ coauthor. An author who submits a manuscript for publicaticn accepts responsiblity foc having property included all, and only, qualified coauthors.

I, the corresponding author, confirm that the authors listed on the manuscript are aware of their authorship status and qualify to be authors on the manuscript according to the guidelines above.

\begin{tabular}{lcc} 
Joalo Coutinho-Rodrigues & October 25, 2016 \\
\hline Print Name & Signature & Date
\end{tabular}

\section{Originality of Content}

ASCE respects the cepyright ownership of other publishers. ASCE requires authors to obtain permission from the copyright holder to reproduce any material that (1) they did not create themselves andior (2) has been previously published, to include the authors' own work for which copyright was transferred to an entity other than ASCE. Each author has a responsiblity to identify materials that require permission by including a citation in the figure or table caption or in extracted text. Materials re-used from an open access repository or in the public domain must still include a citation and URL. if applicable. At the time of submission, authors must provide verification that the copyright owner will permit re-use by a commercial publisher in print and electronic forms with worldwide distribution. For Conference Proceeding manuscripts submitted through the ASCE online submission system, authors are asked to verify that they have permission to re-use content where applicable. Written permissions are not required at submission but must be provided to ASCE if requested. Regardless of acceptance, no manuscript or part of a manuscript will be published by ASCE without proper verification of all necessary permissions to re-use. ASCE accepts no responsibility for verifying permissions provided by the author. Any breach of copyright will result in retraction of the published manuscript.

1, the corresponding author, confirm that all of the content, figures (drawings, charts, photographs, efc.), and tables in the submitted work are either original work created by the authors listed on the manuscript or work for which permission to reuse has been obtained from the creator. For any figures, tables, or text blocks exceeding 100 words from a journal article or 500 words from a book, written permission from the copyright holder has been obtained and supplied with the submissicn.

\begin{tabular}{lcc} 
Joĥ̀o Coutinho-Rodrigues & October 25, 2016 \\
\hline Print name & Signature & Date
\end{tabular}

\section{Copyright Transfer}

ASCE requires that authors or their agents assign copyright to ASCE for all original content published by ASCE. The author(s) warrant(s) that the abovo-cited manuscript is the original work of the author(s) and has never been published in its present form. 


\section{ISENG-1011 R2 - Editor \& Reviewers' comments and answers}

\begin{tabular}{|c|c|}
\hline COMMENTS Editor & ACTION \\
\hline $\begin{array}{l}\text { The editor has requested that minor revisions be made based on the reviewers' evaluations (shown at the end of this email) and submitted for re-review by 12-06- } \\
\text { 2016. This revision will only be seen again by the editor and will not undergo the entire review process. }\end{array}$ & $\begin{array}{l}\text { All requested reviewers' corrections were } \\
\text { made (and are listed in the next Table - } \\
\text { Reviewer \#1)) }\end{array}$ \\
\hline
\end{tabular}

\section{Answers to specific and detailed comments of each Reviewer}

\section{COMMENTS Reviewer \#1}

\section{ACTION}

\section{A. TITLE}

The revised paper still does not reflect adequately the contents of the paper. The paper does not present a methodology for maintenance planning. So the title

could be: "Sidewalk infrastructure assessment using a multicriteria methodology for purposes of maintenance planning."

\section{TECHNICAL WRITING}

There are several sentences that need a rewrite. Several of these are missing a comma sign. Several sentences are missing "The" in front of the sentence. Other needs a rearrangement of the words and sentences. These are two numerous to write here, so I will provide just a few examples:

1. "Sidewalks are the main support for the walking mode of transport and a fundamental piece of commuting, since practically every motorized trip begins or ends with nonmotorized travel."

Could be: "Sidewalks constitute the main guideway for the walking mode of transport and serve as a fundamental infrastructure for personal travel including commuting. This is because practically every motorized trip is preceded or concluded by nonmotorized travel"

The first paragraph of the Introduction should also be modified accordingly.

2. "Assessment of sidewalk performance ..." Should be: "The assessment of sidewalk performance ..."

3. "Results indicate that a considerable ..." Could be: "The results indicate that a considerable ..."

4. This article proposes a multicriteria methodology for this purpose, with an aim at designing ..."

Could be: "This article proposes a multicriteria methodology for this purpose, thus setting the stage for subsequent agency decision regarding maintenance strategy development"

5. "Aware of this, the American Recovery and Reinvestment Act of 2009 provided...."

This could be rewritten as: "Consistent with this realization, agencies strive to provide...."

6. "...leading to the need of developing ..." This could be rewritten as: "...leading to the need for developing ..."

7. "Note also that highly heterogeneous sidewalks should be divided into more homogeneous segments for analysis purposes."

This could be written instead as: "It may be noted that for purposes of the analysis, each sidewalk section that was considered very heterogeneous was

decomposed into multiple homogeneous segments."

These are just examples. If the authors could obtain the services of a technical writer, this good paper could be enhanced further.

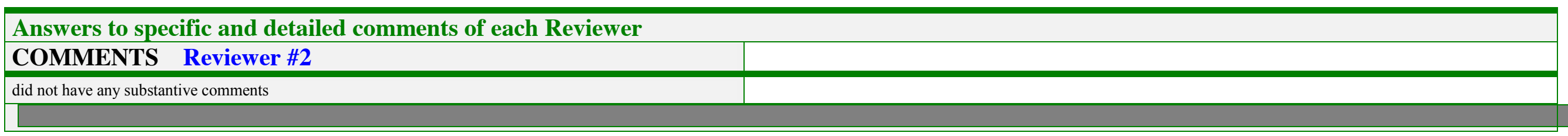

All suggested corrections were done. The whole manuscript was overall doublechecked. 